\title{
PRAGMATISM IN HILL PASTURE RENOVATION
}

\author{
Farm Management Department, Lincoln College
}

\begin{abstract}
Hill pasture renovation methods have been restricted in the past to surface oversowing of unaltered, trampled or bumt pastures. Unfortunately the old pasture recovers and may compete vigorously with the establishing new species, slowing pasture improvement The availability of suitable herbicides has opened up a new opportunity for hill pasture availability

Herbicide applied before oversowing can minimise the competition and allow the new species to establish more easily. The benefits include reduced time to attain optimal stocking rates and improved establishment control, but these are offset by higher initial costs.

The technical aspects of the herbicide establishment methods are overshadowed by the economic factors which control the profitability of the programme, however successfully applied. As the cash flow pattems differ between the traditional renovation and the herbicidebased techniques, changes in interest rates and prices have differential effects. Real interest rates below $7 \%$ make both methods profitable but are more favourable to the herbicide technique at 1987 prices, Also, price increases favour the herbicide method. Among other issues affecting the speed and profitability of development and ultimate gain, managementskill is found to be crucial and dominates both establishment methods.
\end{abstract}

Keywords: hill pastures, renovation, herbicides, interest rates, management skill, profitability

\section{INTRODUCTION}

Herbicides can be used efficiently for hill pasture renovation. In many circumstances their use is more profitable than conventional oversowing and topdressing. However herbicide use changes the annual cash flow as the initial costs of the improvement programme are higher than for the conventional technique.

The principal advantages of the herbicide renovation approach is that income rises more rapidly and the optimum carrying capacity is reached more quickly than for the conventional oversowing and topdressing. Along with the initial costs, and the interest rate, these factors determine the annual cash flows of either system. Simple comparisons of the annual stocking rate attained using either herbicide or oversowing methods of improvement are misleading in any comparison of the techniques. Constraints on the cash flow and correct profitability measures must be accounted for in order to make the comparisons meaningful. The higher the interest rate, the more important these factors become. Also, the relative profitability of each system may also change as the interest rate changes.

Although the ultimate criterion which dominates the decision to improve hill pasture by conventional or herbicide methods is the net profit discounted to the present, cash flow constraints may matter. When borrowed funds are used, the financier is influenced more by risks affecting his security than by the profitability of the proposal. For this reason, for borrowers the simple financial measures may become important.

Although this paper does not pursue these measures they must not be ignored by borrowers. They include the date at which the debt reaches its maximum and the date at which the debt is recovered from profits. They are easily calculated for any programme and are usually referred to as the peak debt, break even and payback dates. 
In order to correctly account for the variation in costs and returns between years, an interest cost should be attached to losses and credited for profits. Used correctly, the procedure leads to a method of discounting in which all profits and losses can be added to obtain a total net profit measure for either of the programmes. This is the true measure of the profitability of each programme and is referred to as the net present value.

The comparisons which follow are taken from a study of the programmes of farmers in the Gisborne district who have renovated pastures using herbicides (Andersen 1988). Farms in the region have also been surveyed by Fitzharris (1983), and the results used to identify the effect of management skill on the profitability of both renovation techniques as well as the length of time taken to complete the programmes.

As will be seen, management skill and the time taken to reach the eventual sustained stocking rate, when interest rates are high, are especially important in determining the profitability of either programme. Although the case studies relate to the Gisborne region, the principles involved have relevance to extensive areas of hill pastures in both islands.

The herbicide-based pasture improvement programmes in the Gisborne region have used glyphosate as their basis since 1980. Conventional hill pasture renovation using oversowing and topdressing has been practised in the region since the late 1940s.

The principal physical result of pasture improvement on the Gisborne farms is summarised in Table 1. The top farmers are defined here as those whose performance falls into the upper $3 \%$ of the population surveyed.

Table 1: Physical measures of pasture improvement

\begin{tabular}{lccccc}
\hline & $\begin{array}{c}\text { Pre-improvement } \\
\text { carrying capacity } \\
\text { Su/ha }\end{array}$ & $\begin{array}{c}\text { Improved } \\
\text { carrying capacity } \\
\text { Herb. OS/TD }\end{array}$ & $\begin{array}{c}\text { Years to attain } \\
\text { optimum production } \\
\text { Herb. OS/TD }\end{array}$ \\
\hline $\begin{array}{l}\text { Average farmers } \\
\text { Top farmers }\end{array}$ & $2.5 \cdot 7.5$ & 11 & 10 & 6 & 6 \\
\hline
\end{tabular}

Undeveloped pasture production is approximately $2.5 \mathrm{su} / \mathrm{ha}$ and the time taken to reach the optimum stocking rate per ha is calculated from this base. The figures are nominal having been seasonally standardised to account for significant annual variations, owing to droughts and deluges (Andersen 1988). Both case study and survey data were used in the compilation of the table.

\section{THE COMPARATIVE PROFITABILITY OF HERBICIDE AND CONVENTIONAL}

\section{TECHNIQUES OF HILL PASTURE RENOVATION}

In the analysis of the financial success of either method of pasture establishment, the principal variables which will create differences between the methods as well as variations between farms are:

Technical The eventual gain in stock per hectare and their improved variables performance;

the time taken to reach the optimum stocking rate The interest rate; costs and prices.

Management Management skill.

Other factors will affect the results, but they are usually less important and will 
not be included to avoid confusion in the analysis.

The outcome of any farm management programme depends on the capability of the manager. Performance indices have been established for the top $3 \%$ of farmers in the Gisborne district (Fitzharris \& Wright, 1983). The results of the conventional renovation programme are shown in Fig. 1, contrasting the programme results for top and average farmers. Although the renovation programmes for top and average farmers show a significant annual income difference when they stabilise $(\$ 11 \mathrm{l} / \mathrm{ha})$, the delay taken to reach this output diminishes the net present value (NPV to a difference of approximately $\$ 60 /$ ha $(\$ 408 \mathrm{NPV}$ and $\$ 348 / \mathrm{ha}$ for the top and average farmers respectively). That means that at $7.5 \%$ real rate of interest, top farmers would receive $\$ 30.60 / \mathrm{ha} /$ year and average farmers $\$ 26.10 / \mathrm{ha} /$ year for their efforts. The noticeably large cash difference in eventual output attributable to management skills is severely reduced by discounting at $7.5 \%$. The interest rate is clearly particularly important through its effect on income in programmes which involve a substantial delay before completion.

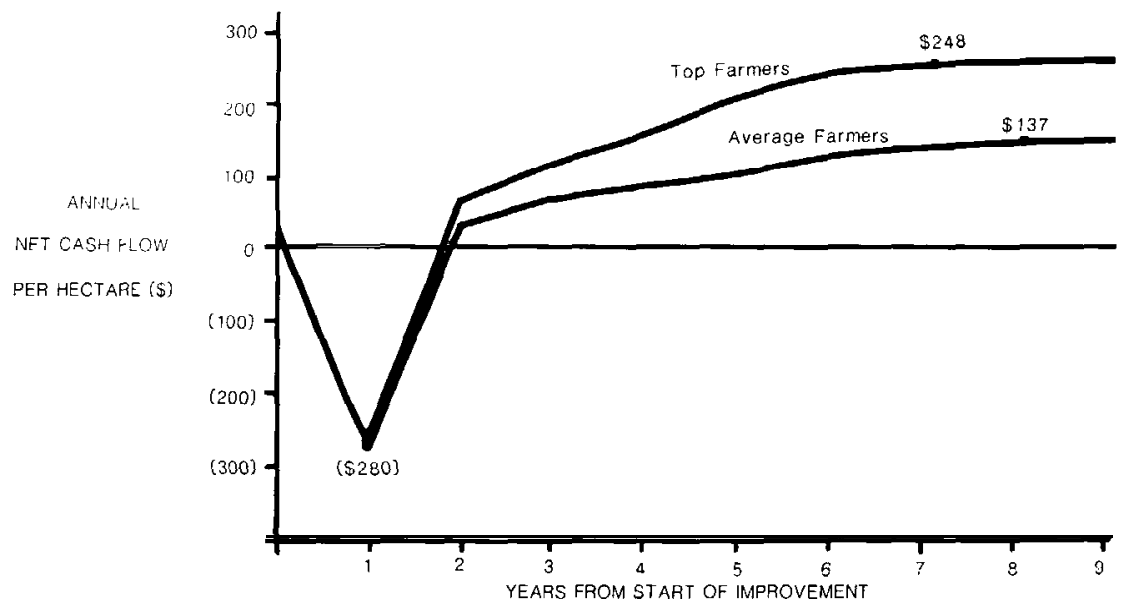

Figure 1: Conventional oversowing: Average and top farm annual net cash flows (2.5 su/ha initial stocking rate, 1987 prices).

Although not shown here, herbicide development costs total $\$ 458 / \mathrm{ha}$ in the first year and for average farmers income stabilises at $\$ 170 /$ ha in the sixth year. For top farmers, income stabilises at $\$ 286 / \mathrm{ha} /$ year from the fifth year on.

The effect of the discount rate and the importance of management skill is explored in Fig. 2 for herbicide programmes. In order to minimise diagrams, the profitability of the programme (on the vertical axis) is given as the NPV/ha instead of the annual net cash flow as in Fig. 1. This enables the effect of the discount (interest) rate to be demonstrated. Real rates of interest are shown in the range from $5 \%$ to $10 \%$. As the interest rate rises, the profitability fallts (to the right). It is apparent that the difference between top and average farmers is more pronounced for herbicide renovation than it was for the conventional method ( $\$ 1460$ and $\$ 400 \mathrm{NPV}$, at $7.5 \%$ discount rate for top and average farmers). In annual yield terms this amounts to $\$ 110$ and $\$ 30 /$ ha/year respectively. For top farmers the advantage of a fall in interest rates is large but for average farmers the gain is only small at the $7.5 \%$ interest rate. Clearly management skill confers an even bigger advantage to 


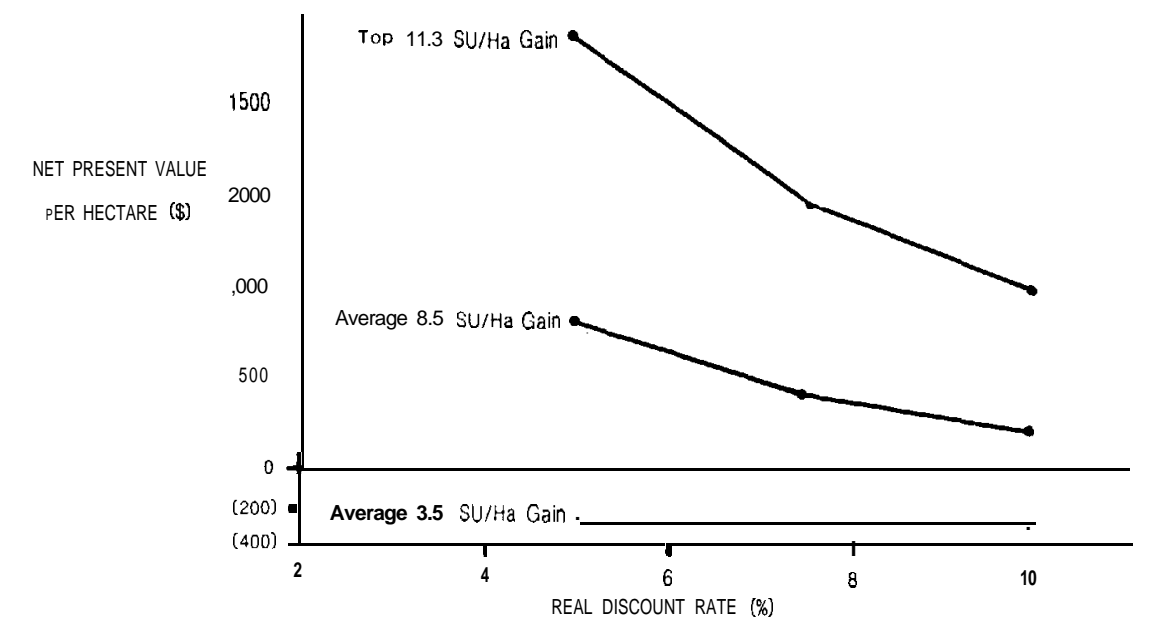

Figure 2: Effect of interest rate on the profitability of herbicide-based hill pasture renovation.

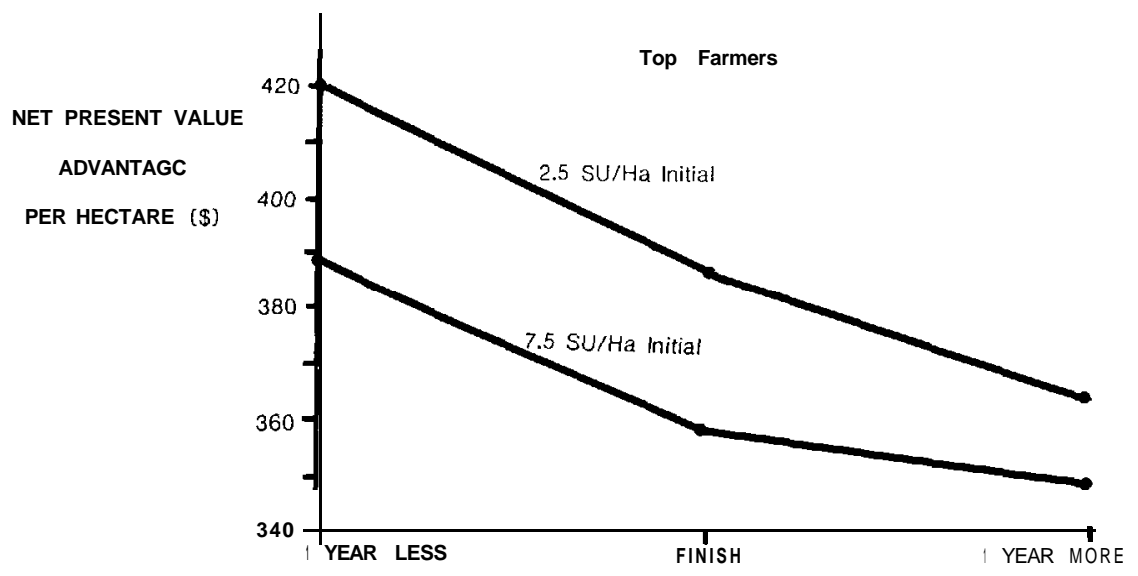

CHANGE IN YEARS TO REACH STABLE INCOME

Figure 3: Development speed effects on the profit advantage of herbicides over conventional oversowing for top farmers at $7.5 \%$ real interest rate.

herbicide programmes than for conventional oversowing and topdressing.

The importance of the interest rate effect becomes more clear when the difference in the length of time the pasture renovation programmes take to reach completion is explored. The vertical axis in Fig. 3 identifies the NPV advantage per ha gained by top farmers who use herbicide-based techniques over top farmers who use conventional oversowing and topdressing. It shows the difference between the two methods. However this advantage is affected by the length of time it takes to reach the final optimal stocking rate. The time to reach completion (at $7.5 \%$ real interest rate) is examined on the horizontal axis by accelerating or slowing the programmes by one year. The two lines on the graph represent cases where 
farmers start from either a 7.5 or a 2.5 su/ha carrying capacity. Naturally the profitability (NPV advantage) is greater when farmers start from a low basic carrying capacity for pasture improvement.

Accelerating both the conventional and the herbicide programmes by one year increases the difference in favour of herbicides and retarding reduces the advantage. The effective change in profitability is due entirely to the interest rate. The combined 2-year shift alters the difference in profitability but the change is not large: $\$ 55$ and $\$ 45$ respectively for initial stocking rates of 2.5 and $7.5 \mathrm{su} / \mathrm{ha}$. As both programmes are profitable and they are accelerated or slowed together, the difference does not change dramatically for these top farmers.

For average farmers (not shown in this diagram) the overall outcome is quite different.

Slowing both programmes increases the financial advantage of the herbicide method, because the conventional method now has a negative NPV. Both programmes are affected negatively, but the conventional programme now makes losses, increasing the advantage of the herbicide technique. The net benefit difference between the pasture improvement techniques for average farmers is almost steady at $\$ 100 /$ ha when the initial stocking rates range from 2.5 to $7.5 \mathrm{su} /$ ha.

The last important variable not yet examined is the product price and with fluctuating exchange rates it is important.

A simple price rise of $30 \%$ without any cost or interest rate change would have a significant effect on the profitability of both the oversowing and herbicide-based systems. For average farmers NPV gains would exceed $\$ 500 /$ ha for both herbicide and conventional systems, starting from a $2.5 \mathrm{su} / \mathrm{ha}$ base. From a $7.5 \mathrm{su} / \mathrm{ha}$ base the gains exceed $\$ 350 /$ ha but favour herbicides by $\$ 100 /$ ha more. For top farmers the gains are proportionately larger.

Table 2 summarises the manner in which each of the variables effects the profitability of the renovation systems. Their effects on both top and average farmers are shown separately.

The table can be expanded, but in the form shown identifies the variables which have the greatest effect on profitability. based on 1987 prices and investment rules for taxation deductions. The tax effect can be approximated by reducing the NPVs in proportion to the equivalent tax payment, but is affected by the tax rules at the time.

Price change effects have not been shown. They are likely to be correlated strongly to changes in the interest rate through the exchange rate/interest rate interaction. They may very well be proportionate to the interest rate change and additive. As the effect is curvilinear, causally correlated to and compounded by the interest rate change, it is hard to describe.

As a single point measure, assume prices rise $30 \%$ in response to a fall from 7.5 to $5.0 \%$ in the real rate of interest. For poor pasture development by average farmers, the NPV will rise by $\$ 1450 /$ ha for conventional development from $\$ 314$, and $\$ 1500$ for herbicide development. For top farmers the gain is much greater but the relative advantage of herbicide - based development is retained.

In summary, it is quite apparent that the dominant factors controlling the financial success of either method of renovating hill pastures are farm management skill and the interest rate. High interest rates and poor skill would ensure disaster. Of the variables which have been described, farmers have most control over their skill. The upgrading of farmers' skills must be given highest priority to effectively apply either renovation technique. However, it is pertinent to conclude that under current conditions of interest rates and prices, farmer gains from improving their 
Table 2: Effects of the principle variables on the profitability of hill pasture renovation using conventional or herbicide-based techniques*

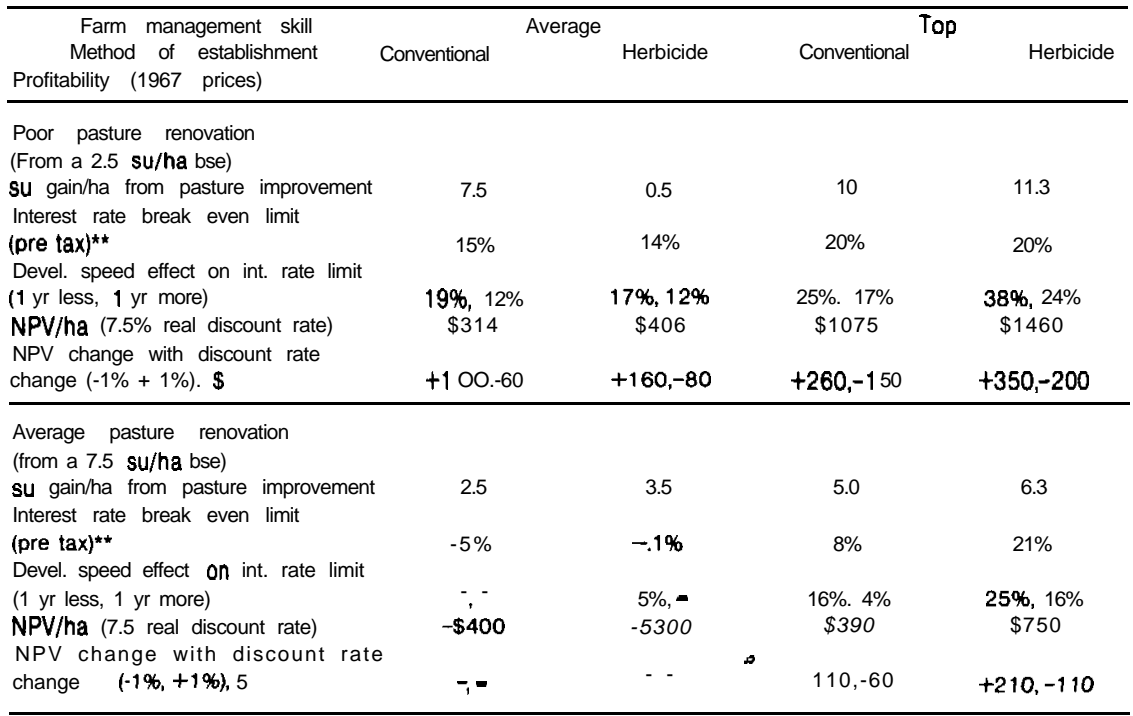

* Cost of structures in the development are excluded

- * Internal rate of return

skills may significantly outweight the benefits of further expansion of pasture renovation. It will be more profitable for average farmers to buy sound management advice than to invest in pasture renovation.

References

Andersen, C.J. 1966 An Economic Evaluation of the Use of Herbicides for Hill Country Pasture Renovation in New Zealand, M.Agr.Sc. Thesis, Lincoln College.

Fitzharris. J.M.; Wright, D.F. 1963. Critical inputs into Gisborne hill country. Proceedings NZ Grasslands Association 45: 27

Fitzharris, J.M. 1963. Farm Monitoring Report: Sheep and Beef. MAF Advisory Service Publication, Wellington. 